ORIGINAL ARTICLE

\title{
Mean Adiponectin Levels and Frequency of Hypoadiponectinemia in Gestational Diabetes Mellitus
}

\author{
Saba Raza', Usman Ali', Adnan Mustafa Zubairi', Erum Salim² \\ 'Department of Chemical Pathology, Dr. Ziauddin University Hospital, North Nazimabad, Karachi, \\ ${ }^{2}$ Clinical Laboratory. Dr. Ziauddin University Hospital, Clifton, Karachi, Pakistan.
}

\begin{abstract}
Background: Insulin resistance, a major pathogenic factor in Gestational Diabetes Mellitus (GDM), has an inverse correlation with adiponectin; therefore, the role of adiponectin in the pathogenesis of GDM has been suggested. The study aimed to determine mean adiponectin levels and the frequency of hypoadiponectinemia in patients with GDM.

Methods: The study was carried out at Dr. Ziauddin University Hospital, Karachi from June 2016 to December 2017. A total of 99 women of age group 15-45 years diagnosed with GDM on Oral Glucose Tolerance Test (OGTT) at 24-28 weeks of gestations were included in the study. Patient's data was recorded on proposed proforma, regarding age, gestational age, parity, ethnicity, Body Mass Index (BMI). Serum samples for quantitative estimation of Adiponectin were collected while performing OGTT and were analyzed on Immunoassay in conjunction with control materials. Mean \pm Std. was calculated for quantitative variables. Percentages and frequencies were calculated for categorical variables. For significant differences between categories, an independent t-test and Chi-square test were used.
\end{abstract}

Results: High frequency of hypoadiponectinemia was observed in GDM women with mean adiponectin levels of $6.90 \pm 2.86 \mathrm{\mu g} / \mathrm{ml}$ (95\%Cl: 6.33 to 7.47$)$. Out of $99 \mathrm{GDM}$ women, 91 (91.92\%) had hypoadiponectinemia while $8(8.08 \%)$ had normal Adiponectin levels. A significant $(p=0.05)$ association was found between BMI and hypoadiponectinemia.

Conclusion: In the majority of GDM females, hypoadiponectinemia was observed. The high frequency of hypoadiponectinemia suggests further large-scale studies, are warranted to ascertain the diagnostic accuracy of adiponectin as a potential biomarker for GDM.

Keywords: Gestational Diabetes; Adiponectin; Pregnancy; Glucose Intolerance.

\section{Corresponding Author:}

\section{Dr. Saba Raza}

Department of Chemical Pathology,

Dr. Ziauddin University Hospital,

North Nazimabad, Karachi, Pakistan.

Email: saba_raza@hotmail.com

https://doi.org/10.36283/PJMD10-1/007

\section{INTRODUCTION}

Pregnancy is a physiological state, which often leads to the development of certain metabolic complications. Gestational Diabetes Mellitus (GDM) is at present the most commonly diagnosed metabolic disorder in pregnant women. GDM is defined as "any degree of glucose intolerance with onset or first recognition during pregnancy" '. The frequency of GDM is increasing worldwide with a higher frequency among the Asian population². A study done in Pakistan reported the frequency of patients diagnosed as GDM on the Glucose Tolerance Test as $26.3 \%{ }^{3}$. According to a study, mean adiponectin levels of $5.43 \pm 2.28$ were found in patients diagnosed with GDM and was proved lower when compared to patients without GDM'.

Gestational Diabetes Mellitus usually develops in the second trimester of pregnancy due to increased 
insulin resistance and insufficient $\beta$-cell compensation. Different diabetogenic hormones secreted from the placenta such as placental lactogen, growth hormone, corticotrophin-releasing hormone and progesterone lead to insulin resistance and thus women whose pancreatic function is not ample to produce sufficient quantities of supplementary insulin to overcome this insulin resistance produced during pregnancy by alterations in diabetogenic hormones develop Gestational Diabetes. Existing data suggest that $\beta$-cell insufficiency and pregnancy-induced insulin resistance in GDM can result from various factors including obesity, inflammation and autoimmune diseases ${ }^{4}$.

Advanced maternal age, obesity, high parity, family history of GDM, or type 2 Diabetes Mellitus are different risk factors associated with GDM. ${ }^{2,3}$ Oral Glucose Tolerance Test (OGTT) is the gold standard for diagnosis of GDM. Several criteria have been proposed to date for the diagnosis of GDM and guidelines vary among different countries 5 . Early screening and diagnosis of GDM is important to avoid neonatal complications as neonatal hypoglycemia, macrosomia, etc. Preeclampsia, increased chances of cesarean section and type 2 diabetes mellitus are among the maternal complications ${ }^{6}$.

Nutrition counseling and diet therapy are helpful in the management of GDM. If target glucose levels are not achieved with diet therapy alone, pharmacotherapy is indicated ${ }^{7}$. Adipose tissue is an important endocrine and metabolically active organ. It secretes various types of adipokines including leptin, adiponectin, resistin, visfatin, and omentin, etc. Adiponectin is a protein hormone and has many functions in the body like enhancement of insulin sensitivity, inflammation resolution and vasculature protection ${ }^{8}$. According to a study, adiponectin levels differ among different ethnicities?.

Adiponectin has a role in process of metabolism of glucose in pregnancy, its levels decrease in pregnancy and are correlated with increased insulin resistance. Although the association of hypoadiponectinemia with GDM is well established as reported in a study, which showed adiponectin levels were significantly decreased in $\mathrm{GDM}^{10}$, yet it was required to study, its significance in our population because of genetic variations exists among different ethnicities. If such a relationship is also found in our patients with GDM, this could be used as a potential biomarker to predict GDM in early pregnancy and hence, appropriate therapeutic interventions and lifestyle modifications can be used to prevent the GDM and its complications. This study aimed to determine mean adiponectin levels and the frequency of hypoadiponectinemia in patients with Gestational Diabetes Mellitus (GDM).

\section{METHODS}

This study was a cross-sectional study conducted from June 2016 to December 2017 in the department of Chemical Pathology at Dr. Ziauddin Hospital, North Nazimabad, Karachi, Pakistan. This study included ninety-nine pregnant females aged 15-45 years diagnosed as GDM by Oral Glucose Tolerance Test (OGTT) between 24 to 28 weeks of gestation. Non-probability consecutive sampling was done. The ethical approval was taken from the Ethical Review Committee (1541019SRPAT) of the Hospital. All women were given information about the purpose of the study and consent was taken. Participant socio-demographic information including age, parity, and ethnicity were collected through interviews. The gestational week was estimated according to the Last Menstrual Period (LMP). The weight of the participant was measured on a digital weighing scale in kilograms. Standing body height was taken by height scale, Body Mass Index (BMI) was calculated (weight in $\mathrm{kg} /$ height in $\mathrm{m}^{2}$ ), and the questionnaire was filled. The diagnosis of GDM was made on OGTT when any of plasma glucose levels (measured Fasting $\geq 92 \mathrm{mg} / \mathrm{dL}$, 1-hour $\geq 180 \mathrm{mg} / \mathrm{dL}, 2$-hour $\geq 153 \mathrm{mg} / \mathrm{dL}$ after $75 \mathrm{gram}$ oral glucose load) are met or exceeded as per American Diabetes Association (ADA) guidelines ${ }^{11}$. Hypoadiponectinemia was labeled with Adiponectin levels below $12.4 \mu \mathrm{g} / \mathrm{ml}^{12}$.

Women with hypertension, GDM history in a previous pregnancy, known case of Diabetes Mellitus (type 1 and 2), family history of Diabetes Mellitus, and evidence of twin pregnancy on ultrasound, evidence of Polycystic Ovary Syndrome on ultrasound, smoker, and history of use of corticosteroids during last 6 months were excluded from the study. Blood samples for laboratory measurement of Adiponectin were drawn in a serum separating tube during the OGTT. The blood samples labeled were sent to the Chemical Pathology department and centrifuged and the sample was transferred to aliquot and frozen at $-70^{\circ} \mathrm{C}$ until testing of adiponectin was analyzed on Immunoassay. Internal quality control materials were used for quality control of the process.

Data was organized and entered on SPSS version 22. Results of quantitative variables as age, gestational age, BMI and serum adiponectin levels were shown as mean and standard deviation. Results of categorical data like parity, ethnicity, and hypoadiponectinemia were expressed as a percentage (\%). The rest of the potential effect modifiers as gestational age, age, BMI, ethnicity, parity were controlled through stratification. The student's t-test and ANNOVA was applied post-stratification for the quantitative outcome (i.e. serum adiponectin levels) and the Chi-square test was applied for the qualitative outcome (i.e. 
hypoadiponectinemia). The result was considered statistically significant with a $p$-value $\leq 0.05$.

\section{RESULTS}

The descriptive statistics of patients are shown in Table 1. Mean Adiponectin levels in patients with GDM were $6.90 \pm 2.86 \mu \mathrm{g} / \mathrm{ml}$ (95\%Cl: 6.33 to 7.47$)$.

Table 1: Clinical statistics of the selected patients for the study.

\begin{tabular}{|c|c|c|c|c|}
\hline $\begin{array}{l}\text { Variables } \\
\text { (Mean } \pm \text { SD) }\end{array}$ & Groups & n (\%) & $\begin{array}{l}\text { Mean Adiponectin } \\
\text { Levels } \mu \mathrm{g} / \mathrm{ml}\end{array}$ & $p$-Value* \\
\hline All Patients & - & $99(100)$ & $6.90 \pm 2.86$ & - \\
\hline Age (Years) (30.0 44.9$)$ & $\begin{array}{l}15-25 \\
26-35 \\
36-45\end{array}$ & $\begin{array}{c}16(16.2) \\
74(74.7) \\
9(9.1)\end{array}$ & $\begin{array}{l}6.80 \pm 3.28 \\
6.79 \pm 2.67 \\
7.95 \pm 3.71\end{array}$ & 0.518 \\
\hline $\begin{array}{l}\text { Gestational Age (Weeks) } \\
(25.40 \pm 0.82)\end{array}$ & $\begin{array}{l}24-25 \\
>25\end{array}$ & $\begin{array}{l}38(38.4) \\
61(61.6)\end{array}$ & $\begin{array}{l}7.00 \pm 2.95 \\
6.83 \pm 2.84\end{array}$ & 0.779 \\
\hline $\begin{array}{l}\text { BMI }\left(\mathrm{Kg} / \mathrm{m}^{2}\right) \\
(28.97 \pm 5.78\end{array}$ & $\begin{array}{c}\text { Normal } \\
\text { (18.50-24.9) } \\
\text { Overweight } \\
\text { (25-29.9) } \\
\text { Obese } \\
(>30)\end{array}$ & $\begin{array}{l}24(24.2) \\
38(38.4) \\
37(37.4)\end{array}$ & $\begin{array}{l}7.59 \pm 3.63 \\
7.37 \pm 2.88 \\
5.98 \pm 2.02\end{array}$ & 0.043 \\
\hline Parity & $\begin{array}{l}\text { Nulliparous } \\
\text { Primiparous } \\
\text { Multiparous }\end{array}$ & $\begin{array}{l}23(23.2) \\
34(34.3) \\
42(42.4)\end{array}$ & $\begin{array}{l}6.57 \pm 2.71 \\
6.67 \pm 2.99 \\
7.26 \pm 2.88\end{array}$ & 0.556 \\
\hline Ethnicity & $\begin{array}{l}\text { Balochi } \\
\text { Muhajir } \\
\text { Punjabi } \\
\text { Pashtun } \\
\text { Sariki } \\
\text { Sindhi }\end{array}$ & $\begin{array}{c}3(3.0) \\
30(30.3) \\
30(30.3) \\
11(11.1) \\
3(3.0) \\
22(22.2)\end{array}$ & $\begin{array}{l}4.20 \pm 1.96 \\
7.51 \pm 2.94 \\
7.15 \pm 3.35 \\
5.90 \pm 1.75 \\
6.26 \pm 2.15 \\
6.68 \pm 2.51\end{array}$ & 0.322 \\
\hline
\end{tabular}

$* p<0.05$ considered significant 
The frequency of hypoadiponectinemia in patients with GDM was $91.92 \%$ (91/99) as shown in Figure 1.

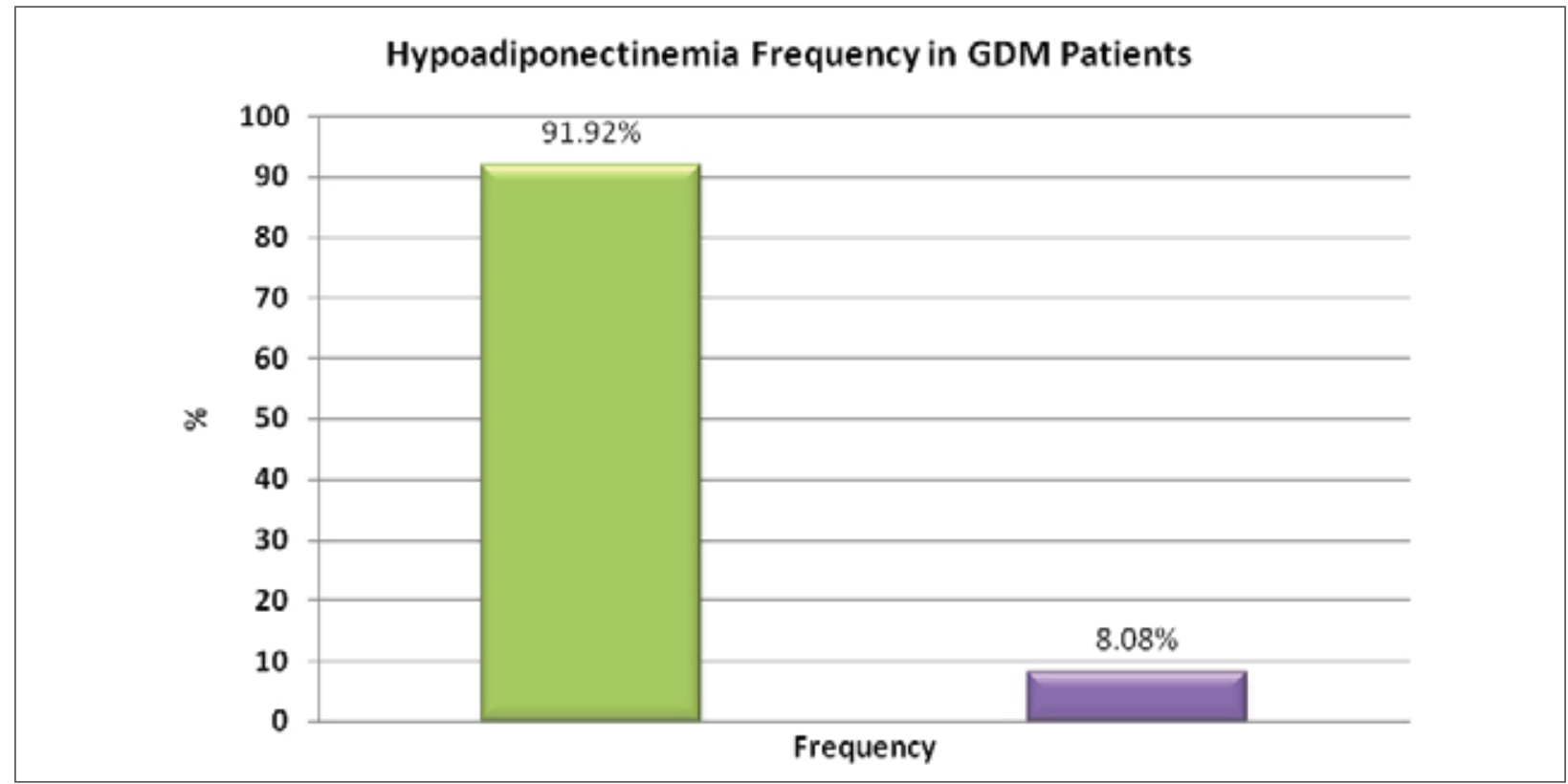

Figure 1: Frequency of hypoadiponectinemia in patients with gestational diabetes mellitus.

The majority (74) of women belonged to the age group of $26-35$ years. Twenty-four (24.2\%) women had normal BMl, thirty-eight (38.3\%) were overweight and thirty-seven (37.3\%) were obese. Patients mainly belonged from Muhajir (30.3\%) and Punjab (30.3\%) ethnicity (Table 1).

Stratification analysis was performed and one way ANNOVA and t-test was applied to compare mean Adiponectin levels, which were not significant among all age groups, gestational age groups, ethnicity, and parity groups though mean Adiponectin levels (Tablel) were low in obese women as compared to normal and overweight women.

No significant difference was found in the frequency of hypoadiponectinemia using $\mathrm{CHI}$-square test regarding age groups, gestational age, parity and ethnicity groups (Table 2) while the frequency of hypoadiponectinemia was high in obese cases $(p=0.05)$ (Figure 2).

Table 2: Frequency of hypoadiponectinemia in patients with gestational diabetes mellitus by age, gestational age, parity and ethnicity.

\begin{tabular}{|c|c|c|c|c|c|c|}
\hline \multirow{2}{*}{ Variables } & \multirow{2}{*}{ Groups } & \multirow{2}{*}{$\begin{array}{c}n \\
(\%)\end{array}$} & \multicolumn{2}{|c|}{ Hypoadiponectinem ia } & \multirow{2}{*}{$p$-Value* } & \multirow{2}{*}{ Chi-Square } \\
\hline & & & Positive & Negative & & \\
\hline Age (Years) & $\begin{array}{l}15-25 \\
26-35 \\
36-45\end{array}$ & $\begin{array}{c}16(16.2) \\
74(74.7) \\
9(9.1)\end{array}$ & $\begin{array}{c}15(93.8 \%) \\
69(93.2 \%) \\
7(77.8 \%)\end{array}$ & $\begin{array}{c}1(6.3 \%) \\
5(6.8 \%) \\
2(22.2 \%)\end{array}$ & 0.263 & 2.67 \\
\hline $\begin{array}{l}\text { Gestational } \\
\text { Age (Weeks) }\end{array}$ & $\begin{array}{c}24-25 \\
>25\end{array}$ & $\begin{array}{l}38(38.4) \\
61(61.6)\end{array}$ & $\begin{array}{l}35(92.1 \%) \\
56(91.8 \%)\end{array}$ & $\begin{array}{l}3(7.9 \%) \\
5(8.2 \%)\end{array}$ & 0.957 & 0.003 \\
\hline Parity & $\begin{array}{l}\text { Nulliparous } \\
\text { Primiparous } \\
\text { Multiparous }\end{array}$ & $\begin{array}{l}23(23.2) \\
34(34.3) \\
42(42.4)\end{array}$ & $\begin{array}{l}22(95.7 \%) \\
32(94.1 \%) \\
37(88.1 \%)\end{array}$ & $\begin{array}{l}1(4.3 \%) \\
2(5.9 \%) \\
5(11.9 \%)\end{array}$ & 0.477 & 1.48 \\
\hline Ethnicity & $\begin{array}{l}\text { Balochi } \\
\text { Muhajir } \\
\text { Punjabi } \\
\text { Pashtun } \\
\text { Sariki } \\
\text { Sindhi }\end{array}$ & $\begin{array}{c}3(3.0) \\
30(30.3) \\
30(30.3) \\
11(11.1) \\
3(3.0) \\
22(22.2)\end{array}$ & $\begin{array}{c}3(100 \%) \\
27(90 \%) \\
26(86.4 \%) \\
11(100 \%) \\
3(100 \%) \\
21(95.5 \%)\end{array}$ & $\begin{array}{c}0(0 \%) \\
3(10 \%) \\
4(13.3 \%) \\
0(0 \%) \\
0(0 \%) \\
1(4.5 \%)\end{array}$ & 0.680 & 3.15 \\
\hline
\end{tabular}

$* p<0.05$ considered significant 


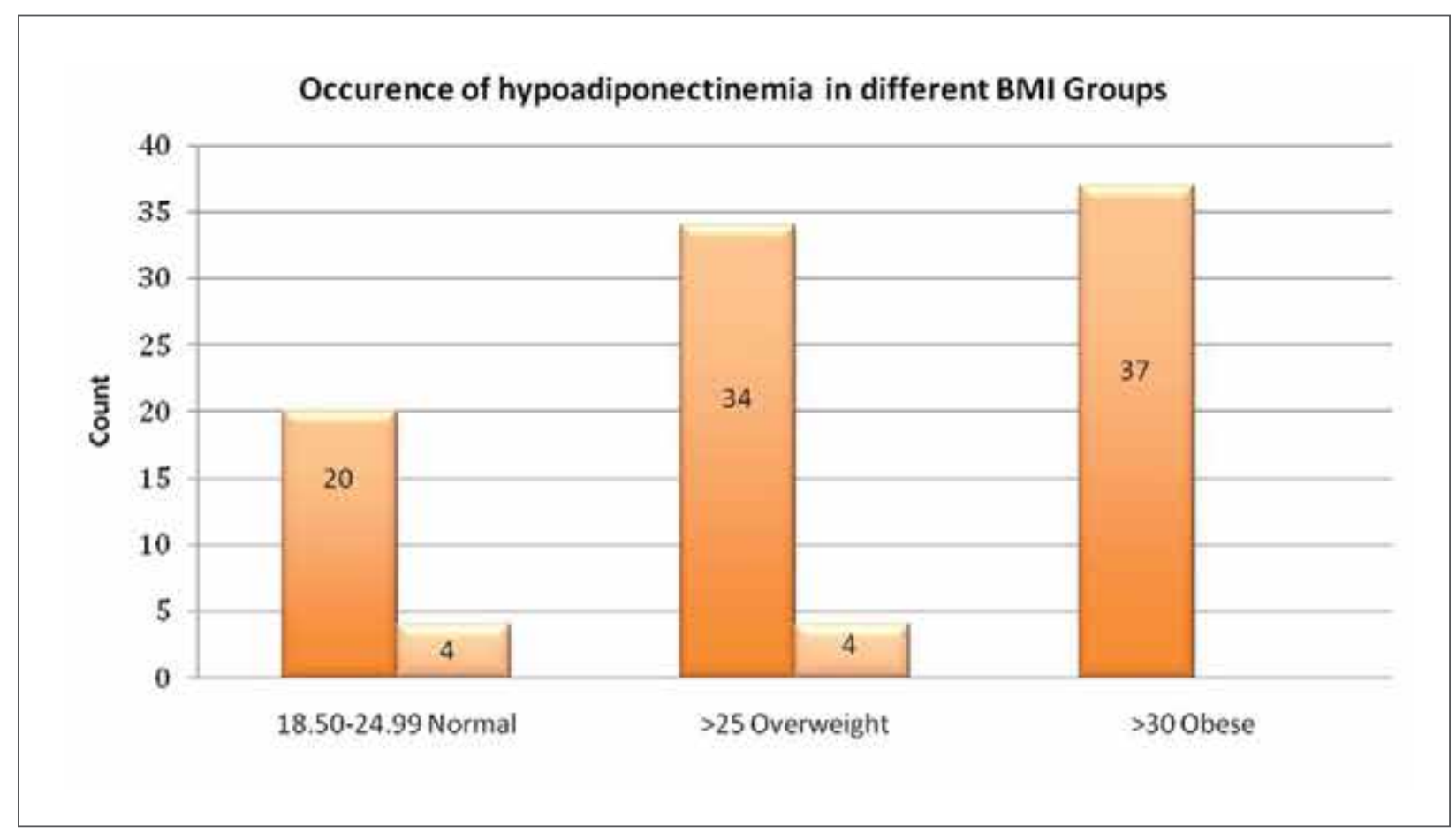

Figure 2: Frequency of hypoadiponectinemia in various groups of BMI.

\section{DISCUSSION}

Among all pregnant females diagnosed with GDM 91.92\% (91/99) had decreased Adiponectin levels labeled as hypoadiponectinemia (when using a cutoff value of $<12.4 \mu \mathrm{g} / \mathrm{ml}$ ) compared to study conducted by Chen et al. in 2012 which stated the frequency of hypoadiponectinemia as $50.7 \%$ in GDM patients (using a cutoff of $<9 \mu \mathrm{g} / \mathrm{ml}$ ). At the cutoff of $<9 \mu \mathrm{g} / \mathrm{ml}$, frequency of GDM in our study was $80.80 \%$, which is high in comparison with the study done by Chen et $\mathrm{al}^{13}$. Another study found decreased concentrations of Adiponectin in $G M^{14}$. In our study, mean adiponectin levels in patients with GDM was $6.90 \pm 2.86 \mu \mathrm{g} / \mathrm{ml}$ compared to mean adiponectin levels of $7.06 \pm 3.69 \mu \mathrm{g} / \mathrm{ml}$. This can be due to ethnic variability, and genetic control of the production, secretion and degradation of adiponectin ${ }^{15}$.

The mean age of pregnant females in our study, was $30 \pm 4.81$ years whereas, a study done in India in 2016 showed the mean age of pregnant females with GDM 28.9+3.64 years $^{16}$. The mean gestational age (weeks) was $25.40 \pm 0.82$ compared to a study mean gestational age was $27.1 \pm 0.6^{15}$. This study showed a significant difference ( $p$ value=0.043) in mean adiponectin levels among BMI groups with lower mean adiponectin levels in obese women which was supported by a study also showing low levels in obese women with GDM ${ }^{17}$.

Years of research on adiponectin has emerged as a sizeable factor in the pathogenesis of GDM that may link insulin resistance and beta-cell dysfunction ${ }^{18,19}$. Some studies found that low levels of Adiponectin were linked with an increased risk of developing GDM and may be utilized as a biomarker in the first trimester of pregnancy to predict the risk of developing GDM in pregnant females ${ }^{20-23}$.

Adiponectin levels vary among different ethnicities ${ }^{24,25}$. In our region, not much attention has been paid to the assess frequency of hypoadiponectinemia in GDM. When compared among different ethnicities in our population, serum adiponectin levels varied and were comparatively lower in Balochi subjects with mean adiponectin levels of $4.20 \pm 1.96 \mu \mathrm{g} / \mathrm{ml}$. In our study, which included GDM patients from $24-28^{\text {th }}$ weeks of gestation, we found a high frequency of hypoadiponectinemia in GDM, making it a potentially good marker for screening of GDM. On the other hand, adiponectin levels have been shown to exhibit variation through different trimesters of pregnancy ${ }^{14}$.

The limitations of my study were lack of multicenter data collection, lack of information about pre-pregnancy adiponectin concentrations, in the first trimester of pregnancy and after delivery to determine whether adiponectin concentrations have returned to normal. Our study was a cross-sectional study, therefore further large scale diagnostic accuracy studies are required to be performed in our population, to establish the sensitivity, specificity, Receiver Operating Characteristic (ROC) curve so that a reliable cutoff can be obtained for screening and diagnosing Gestational Diabetes Mellitus. 
We are quite optimistic that advanced research about the processes involved in the development of insulin resistance during pregnancy and different phenomena causing a decrease in adiponectin levels in GDM will lead to proactive approaches to improve the health of mothers and neonates in the times to come.

\section{CONCLUSION}

The mean Adiponectin levels in women with GDM was $6.90 \pm 2.86 \mu \mathrm{g} / \mathrm{ml}$ and $91.92 \%$ cases were having hypoadiponectinemia. The findings suggest that a decline in Adiponectin levels may play a part in the development of insulin resistance in patients with GDM.

\section{ACKNOWLEDGEMENTS}

The authors would like to acknowledge Ms. Sadia Ghani for assistance in sample analysis.

\section{CONFLICT OF INTEREST}

There is no conflict of interest to be declared.

\section{ETHICS APPROVAL}

The study approval was obtained from the Ethics Review Committee of the Ziauddin University Hospital (1541019SRPAT).

\section{PATIENT CONSENT}

Verbal and written informed consent was obtained from all patients.

\section{AUTHORS' CONTRIBUTION}

SR, ES and UA designed the project, SR gathered the writing material and done the data collection activity. UA performed the statistical analysis. AMZ and ES reviewed the manuscript.

\section{REFERENCES}

1. Saini V, Kataria M, Yadav A, Jain A. Role of leptin and adiponectin in gestational diabetes mellitus: a study in a North Indian tertiary care hospital. Internet J Med Update. 2015;10(1):11-4.

2. Lee KW, Ching SM, Ramachandran V, Yee A, Hoo FK, Chia YC, et al. Prevalence and risk factors of gestational diabetes mellitus in Asia: a systematic review and meta-analysis. BMC Pregnancy Childbirth. 2018;18(1):494-513.

3. Fatima S, Rehman R, Alam F, Madhani S, Chaudhry B, Khan TA. Gestational diabetes mellitus and the predisposing factors. J Pak Med Assoc. 2017;67(2):261-265.

4. Sharafat J, Ahmed U, Anwar MK, Saad K. Association of adiponectin with insulin resistance in gestation- al diabetes mellitus. Pak J Physiol. 2019;15(2):25-27. 5. Bhavadharini B, Uma R, Saravanan P, Mohan V. Screening and diagnosis of gestational diabetes mellitus - relevance to low and middle income countries. Clin Diabetes Endocrinol. 2016;2(13)1-8.

6. Makwana M, Bhimwal RK, Ram C, Mathur SL, Lal K, Mourya H. Gestational diabetes mellitus with its maternal and foetal outcome: a clinical study. Int J Adv Med. 2017;4(4):919-925.

7. Walker JD. NICE guidance on diabetes in pregnancy: management of diabetes and its complications from preconception to the postnatal period. NICE clinical guideline 63. London, March 2008. Diabetic Med. 2008;25(9):1025-1027.

8. Wang Z, Scherer P. Adiponectin, the past two decades. J Mol Cell Biol. 2016;8(2):93-100.

9. Parvaresh Rizi E, Teo Y, Leow MK, Khoo EY, Yeo CR, Chan E, et al. Ethnic differences in the role of adipocytokines linking abdominal adiposity and insulin sensitivity among Asians. J Clin Endocrinol Metab. 2015; 100(1 1):4249-4256.

10. Mohammadi T, Paknahad Z. Adiponectin concentration in gestational diabetic women: a case-control study. Clin Nutr Res. 2017;6(4):267-276.

11. American Diabetes Association. 2. Classification and diagnosis of diabetes: standards of medical care in diabetes-2019. Diabetes care. 2019 Jan 1;42(Supplement 1):S13-S28.

12. Retnakaran R, Hanley A, Raif N, Hirning C, Connelly $P$, Sermer $M$, et al. Adiponectin and beta cell dysfunction in gestational diabetes: pathophysiological implications. Diabetologia. 2005;48(5):993-1001.

13. Chen X, Scholl TO, Stein TP. Hypoadiponectinemia: Association with risk of varying degrees of gestational hyperglycemia and with maternal ethnicity. Int J Diabetes Mellitus. 2012;02(02): 196-202.

14. Bozkurt L, Göbl CS, Baumgartner-Parzer S, Luger A, Pacini G, Kautzky-Willer A. Adiponectin and leptin at early pregnancy: association to actual glucose disposal and risk for GDM-A prospective cohort study. Int J Endocrinol. 2018;2018:546 3762:1-9.

15. Naghshineh E, Faryadras N, Rouholamin S. Is there any relation between adiponectin levels in the first trimester of pregnancy and gestational diabetes? Womens Health Gynecol. 2016;2(4):32-35.

16. Bhograj A, Suryanarayana KM, Nayak A, Murthy SN, Dharmalingam M, Kalra P. Serum adiponectin levels in gestational diabetes mellitus. Indian J Endocrinol Metab. 2016;20(6):752-755.

17. Ramirez VI, Miller E, Meireles CL, Gelfond J, Krummel DA, Powell TL. Adiponectin and IGFBP-1 in the development of gestational diabetes in obese mothers. BMJ Open Diabetes Res Care. 2014;2(1): 1-8.

18. Plows J, Stanley J, Baker P, Reynolds C, Vickers M. The pathophysiology of gestational diabetes mellitus. Int J Mol Sci. 2018;19(11):3342: 1-21.

19. Barbe A, Bongrani A, Mellouk N, Estienne A, Kurowska P, Grandhaye J, et al. Mechanisms of adiponectin action in fertility: An overview from gametogenesis to gestation in humans and animal models in normal and pathological conditions. Int J 
Mol Sci. 2019;20(7):1526.

20. Madhu S V, Bhardwaj S, Jhamb R, Srivastava H, Sharma S, Raizada N. Prediction of gestational diabetes from first trimester serum adiponectin levels in Indian Women. Indian J Endocr Metab. 2019;23:536-539.

21. Thagaard IN, Krebs L, Holm JC, Lange T, Larsen T, Christiansen M. Adiponectin and leptin as first trimester markers for gestational diabetes mellitus: a cohort study. Clin Chem Lab Med. 2017;55(11):1805-1812 22. lliodromiti S, Sassarini J, Kelsey TW, Lindsay RS, Sattar $\mathrm{N}$, Nelson SM. Accuracy of circulating adiponectin for predicting gestational diabetes: a systematic review and meta-analysis. Diabetologia. 2016;59(4):692-699.
23. Lorenzo-Almorós A, Hang T, Peiró C, Soriano-Guillén L, Egido J, Tuñón J, et al. Predictive and diagnostic biomarkers for gestational diabetes and its associated metabolic and cardiovascular diseases. Cardiovasc Diabetol. 2019;18(1):1-16.

24. Chen X, Scholl T. Ethnic differences in maternal adipokines during normal pregnancy. Int J Environ Res Public Health. 2015;13(1):8:1-13.

25. Jara A, Dreher M, Porter K, Christian L. The association of maternal obesity and race with serum adipokines in pregnancy and postpartum: Implications for gestational weight gain and infant birth weight. Brain Behav Immun. 2020;3:100053:1-8. 